\title{
Methylphenidate extended-release oral suspension for the treatment of attention- deficit/hyperactivity disorder: a practical guide for pharmacists
}

This article was published in the following Dove Press journal:

Integrated Pharmacy Research and Practice

17 October 2017

Number of times this article has been viewed

\author{
Joshua Caballero' \\ Edress H Darsey² \\ Faith Walters ${ }^{2}$ \\ Heidi W Belden² \\ 'Department of Clinical and \\ Administrative Sciences, College of \\ Pharmacy, Larkin Health Sciences \\ Institute, Miami, FL, ${ }^{2}$ Pfizer Inc, \\ New York, NY, USA
}

\begin{abstract}
Attention-deficit/hyperactivity disorder (ADHD) is a neurodevelopmental condition that affects children, adolescents, and adults worldwide. The purpose of this review was to inform pharmacists of the numerous options to treat ADHD, with a focus on one of the more recently approved formulations, methylphenidate extended-release oral suspension (MEROS). Symptoms of ADHD can negatively impact an individual's health and quality of life and impair function in multiple settings. Psychostimulants such as methylphenidate- and amphetaminebased agents are first-line pharmacologic treatments for ADHD. However, there are multiple formulations, including immediate release (administered two to three times/day), solid extended release (ER), or transdermal patch. MEROS is a once daily, long-acting liquid preparation that has demonstrated favorable safety and efficacy in patients with ADHD. MEROS may improve treatment adherence in patients who cannot tolerate or have difficulties administering pill or transdermal patch formulations.
\end{abstract}

Keywords: drug formulation, administration, adherence

\section{Introduction}

Attention-deficit/hyperactivity disorder (ADHD) is a chronic neurodevelopmental disorder characterized by symptoms of inattention, impulsivity, and hyperactivity. ${ }^{1,2}$ The onset of ADHD most commonly occurs in childhood, ${ }^{3}$ but for a number of individuals, symptoms continue into adolescence and adulthood. ${ }^{4}$ ADHD can substantially impair an individual's ability to function in school, work, home, and other social environments, resulting in significant academic, social, and family problems. ${ }^{5-7}$ Individuals may experience higher rates of unintentional injuries, emergency department visits, suspension, expulsion, and dropping out of school and are at a greater risk of developing other psychiatric disorders and drug dependence. . $^{4-6-10}$ ADHD is also associated with a considerable socioeconomic burden, primarily resulting from reduced productivity, income loss, and increased health care costs. ${ }^{11}$ Despite the socioeconomic burden associated with ADHD, many adults and children with ADHD remain undiagnosed and untreated. ${ }^{12,13}$ Given the numerous pharmacologic agents and formulations available, the purpose of this review was to inform pharmacists of these available pharmacologic options and formulations, with a focus on one of the more recently approved formulations, methylphenidate extended-release oral suspension (MEROS).
Correspondence: Joshua Caballero Department of Clinical and Administrative Sciences, College of Pharmacy, Larkin Health Sciences Institute, 1830I North Miami Avenue, Suite I, Room 2202, Miami, FL 33169, USA

Tel +I 3057607507

Email jcaballero@ularkin.org 


\section{Treatment of ADHD}

Clinical practice guidelines published by the American Academy of Child and Adolescent Psychiatry (AACAP) ${ }^{2}$ and the American Academy of Pediatrics (AAP) ${ }^{14}$ recommend pharmacologic and behavioral interventions for individuals with ADHD. Pharmacotherapies recommended by these guidelines include amphetamine- and methylphenidate-based psychostimulants, as well as nonstimulants (US Food and Drug Administration [FDA]-approved stimulant and nonstimulant medications; Table 1). ${ }^{2,14}$ Psychostimulants have been the standard of care for ADHD for several decades. ${ }^{15}$ Nonstimulants (eg, serotonin-norepinephrine reuptake inhibitors, $\alpha_{2}$ adrenergic receptor agonists, tricyclic antidepressants, bupropion) are sometimes prescribed for individuals whose symptoms do not improve adequately with stimulants, who experience intolerable side effects, and/or have certain comorbidities. ${ }^{3,16,17}$ Currently, only three nonstimulants have FDA approval for the treatment of ADHD (Table 1). ${ }^{18-21}$

Psychostimulants increase dopamine levels in the brain, thereby improving concentration and reducing hyperactive and impulsive behaviors. The primary pharmacologic action of methylphenidate-based treatments is the inhibition of plasma membrane dopamine and noradrenaline transporters. Amphetamine-based compounds are thought to inhibit dopamine and norepinephrine transporters, reverse dopamine uptake by dopamine transporters, and promote release of dopamine via interactions with vesicular monoamine transporter $2 .{ }^{22}$ Regardless of mechanism of action, both methylphenidate- and amphetamine-based stimulants have demonstrated favorable safety and efficacy for the treatment of children, adolescents, and adults with ADHD. ${ }^{21,23}$

For a number of years, stimulants were only available as immediate-release (IR) formulations, which are characterized by a short duration of action, necessitating multiple daily administrations (eg, two to three times a day). ${ }^{2}$ This requirement can be particularly problematic for children who attend school, resulting in complications related to privacy, stigmatization by classmates, and risk of nonadherence to treatment., ${ }^{2,24}$ As a result, prescriptions for extended-release (ER) formulations now exceed those for IR formulations for children with ADHD. ${ }^{24-26}$ Some major advantages of ER formulations for school-age children are better pharmacokinetic profile (eg, lower peak concentrations) and the ability to provide all-day coverage, which avoids the necessity to administer additional doses during school or aftercare programs. ${ }^{2}$

Despite the availability of these ER formulations, many require children to swallow an intact tablet/capsule or wear a transdermal patch. However, some children have diffi- culty swallowing tablets or cannot tolerate the transdermal patch. ${ }^{27-30}$ The instructions for some capsule formulations of some ER formulations allow for opening the capsule and dispersing the contents into food (eg, yogurt, apple sauce) or liquid (eg, water, orange juice) for administering to patients who are unable to swallow tablets. ${ }^{31-33}$ There is concern among clinicians, however, that such modifications to treatment administration could result in inaccurate dosing (eg, food microwaved, contents not completely eaten). ${ }^{34}$ Furthermore, ER delivery mechanisms can be compromised if the medication is chewed rather than swallowed, resulting in dose dumping. ${ }^{35}$ Therefore, a liquid ER formulation of methylphenidate or amphetamine may be beneficial for the treatment of ADHD, as it will allow for an easier dosing regimen compared with IR formulations and circumvent challenges posed by ER tablet or capsule formulations. ${ }^{35}$

Although stimulant and nonstimulant medications have demonstrated efficacy for the treatment of ADHD, metaanalyses of double-blind, placebo-controlled trials have demonstrated a superior effect size for stimulants in both children and adults. ${ }^{36,37}$ Owing to the availability of a range of different classes and formulations of ADHD pharmacotherapies, it is important that pharmacists play a key role in medication monitoring and patient counseling. Key points for pharmacists to consider when dispensing ADHD medications are summarized in Table $2 .^{38-41}$

\section{MEROS}

MEROS is a long-acting liquid preparation (Quillivant XR; NextWave Pharmaceuticals, Inc, a subsidiary of Pfizer Inc, New York, NY, USA) approved by the FDA in 2012 for the treatment of ADHD in patients aged 6 years or older. ${ }^{42,43}$ MEROS was designed with the goal of combining the desired pharmacokinetic characteristics of both IR and ER formulations of methylphenidate: rapid initial absorption leading to a rapid clinical effect followed by an extended period of release allowing for the clinical effect to last throughout the day. ${ }^{35}$ MEROS is composed of cationic polymer matrix particles that bind D,L-threo-methylphenidate racemic mixture via an ion exchange mechanism. The particles are covered with a coating of various thicknesses to confer ER properties. The resulting preparation is a blend of uncoated and coated particles that is $\sim 20 \%$ IR and $\sim 80 \%$ ER methylphenidate. ${ }^{44}$ MEROS is supplied as a powder that should be reconstituted by the pharmacist prior to dispensing to produce an oral suspension that does not require refrigeration. Reconstituted MEROS should be stored at $25^{\circ} \mathrm{C}$ (range $15-30^{\circ} \mathrm{C}$ ) and is stable for up to 4 months. ${ }^{42}$ Full instructions for use of MEROS are presented in Figure 1. 





Bioequivalence of MEROS versus IR methylphenidate oral solution was demonstrated in a pharmacokinetic study in healthy adults such that the relative bioavailability of MEROS $60 \mathrm{mg}$ versus IR methylphenidate $60 \mathrm{mg}$ oral solution (given as two $30 \mathrm{mg}$ doses 6 hours apart) was $95 \% .{ }^{35} \mathrm{In}$ a randomized, dose-optimized, laboratory, school efficacy and safety study conducted over 6-8 weeks in 45 subjects aged 6-12 years, MEROS significantly improved symptoms of ADHD at the primary efficacy end point of 4 hours post dose versus placebo (Swanson, Kotkin, Agler, M-Flynn, and Pelham [SKAMP] rating scale ${ }^{45}$ - combined score was 7.12 [95\% CI: 4.85, 9.39] for MEROS versus 19.58 [17.31, 21.86] for placebo; $P<0.0001)$. These improvements were observed 45 minutes post dose and continued for up to 12 hours. ${ }^{44}$ MEROS treatment also improved numerous secondary efficacy outcomes including Permanent Product Measure of Performance ${ }^{46}$ (PERMP; a skill-adjusted, written math test designed to assess attention and the ability to complete written seat work), ADHD Rating Scale $\mathrm{IV}^{47}$ (ADHD-RS), Clinical Global Impression - Severity ${ }^{48}$ (CGIS), and Clinical Global Impression - Improvement ${ }^{48}$ (CGI-I) scale scores. ${ }^{49}$ At each time point tested for the PERMP, the number of problems attempted and the number answered correctly were significantly higher during treatment with MEROS compared with placebo $(P<0.0001$ to $P=0.0155$, number attempted; $P<0.0001$ to $P=0.0016$, number correct)..$^{49}$ As with the SKAMP - combined score, the treatment differences for MEROS versus placebo on PERMP reached statistical significance at 45 minutes post dose $(P<0.0001$, both number attempted and number correct) and remained statistically significant until the last post-dose assessment at 12 hours ( $P=0.0019$, number attempted; $P=0.0008$, number correct) ${ }^{44,49}$ Mean ADHD-RS total scores improved from $39.3( \pm 7.6)$ at baseline to $12.6( \pm 6.3)$ at the end of the openlabel phase. The percentage of responders (defined as $\geq 50 \%$ improvement in ADHD-RS) was $87.2 \%$. As measured by the CGI-S at baseline, $63.3 \%$ of participants were considered moderately ill and $25 \%$ were considered markedly ill; however, at the end of the open-label phase, most participants were considered borderline ill (51.3\%) or not ill at all (20.5\%), and no participants were considered either markedly or severely ill. Furthermore, at the end of the open-label phase, all participants were considered either much improved ( $41 \%$ ) or very much improved (59\%) as measured by CGI-I. ${ }^{49}$

\section{Safety}

The safety and tolerability profile of MEROS is comparable with that of other methylphenidate formulations. ${ }^{44,49}$ In the 
Table 2 Medication monitoring and patient counseling

What the pharmacist needs to know

- Titration of stimulant medication is often necessary at the initiation of therapy - the pharmacist should expect prescriptions with incremental dosing increases in the first several months of treatment

- Special ordering may be required as stimulant medications are Schedule Cll drugs

- The FDA requires distribution of a Patient Medication Guide sheet specific for the drug being dispensed

- Counsel individuals with ADHD (or parents/caregivers) to emphasize the importance of taking the proper dose at the appropriate time, warn or inquire about potential adverse effects, and caution patients about the risks of taking pseudoephedrine-containing OTC cold/allergy medication concomitantly with stimulants

- Provide education to patients (or parents/caregivers) when administration of the medication dispensed is a change from the original dosage form

- Review black box warning for stimulant medications dispensed

- Monitor for signs of abuse, misuse, and diversion of stimulant medications

Notes: Data from these studies. ${ }^{38-41}$

Abbreviations: FDA, US Food and Drug Administration; ADHD, attention-deficit/hyperactivity disorder; OTC, over the counter.

randomized, double-blind, placebo-controlled, crossover trial of MEROS in 45 children aged 6-12 years, the most common treatment-emergent adverse events (TEAEs) during the open-label phase were decreased appetite $(55.6 \%)$, upper abdominal pain (42.2\%), affect lability (26.7\%), initial insomnia (22.2\%), insomnia (17.8\%), and headache (17.8\%). In the double-blind phase, TEAEs generally had a lower incidence than in the open-label phase, with only affect lability reported in $\geq 5 \%$ of subjects receiving MEROS (MEROS: $8.9 \%$; placebo: $2.2 \%){ }^{44,49}$ No severe TEAEs were reported during the double-blind phase, and three subjects reported three severe TEAEs each (ie, affect lability, aggression, initial insomnia) during the open-label phase. ${ }^{44,49}$ Two subjects withdrew from the study during the open-label phase because of these TEAEs (ie, affect lability, aggression). ${ }^{49}$ There were no deaths or serious adverse events and no occurrences of suicidal ideation or behavior during the study. ${ }^{44,49}$

\section{Reconstitution and administration}

There are several key points for pharmacists to consider when dispensing MEROS. ${ }^{42}$ First, reconstitution of the powder with water followed by vigorous shaking of the bottle for at least 10 seconds is critical to ensure the powder is fully suspended. It is important that the individual with ADHD, parent, or caregiver should be informed of the importance of vigorously shaking the bottle for at least 10 seconds prior to measuring each dose. Second, the bottle adapter, which is supplied in each box of MEROS, must be fully and securely inserted into the neck of the bottle, and the tip of the oral dosing dispenser (also supplied in every box of MEROS) must be inserted into the upright bottle adapter before the bottle is turned upside down and the required volume is drawn into the oral dosing dispenser. Finally, the dose should be administered directly into the patient's mouth.

\section{Conclusion}

ADHD is a chronic disorder with debilitating symptoms that is often present in childhood and adolescence but can persist into adulthood. Despite the increasing prevalence of ADHD, a number of individuals remain undiagnosed and untreated, ${ }^{12,13,50}$ which is possibly due to the considerable stigma associated with the disorder. ${ }^{50,51}$ For patients diagnosed and receiving treatment, many are restricted to receiving medications that are inconvenient and/or not appropriate for their age or stage of development. ${ }^{2,24,29}$ IR formulations were the mainstay of ADHD therapy for many years but are inconvenient due to their short duration and multiple dosing schedules. For many patients with ADHD, ER formulations represent a more convenient option due to a once daily dosing regimen. ${ }^{2}$ However, a number of challenges associated with administration of ER formulations remain (eg, children's inability to swallow tablets, dermal reactions to topical patches). ${ }^{27-30}$ In addition, unreliable dosing and kinetics may occur when ER products are crushed or opened and contents are administered with food or drink. ${ }^{52}$

MEROS is a once-daily, long-acting, liquid preparation of methylphenidate that may be an option for patients who cannot tolerate or have difficulties with administering pill or transdermal patch formulations. ${ }^{35}$ MEROS has been shown in clinical studies to improve symptoms and exhibit a safety and tolerability profile similar to other stimulant ADHD medications. ${ }^{44,49}$ However, it is important that pharmacists ensure that MEROS is properly dispensed and patients or their family members are provided with thorough instructions regarding its use.

\section{Acknowledgment}

Medical writing support was provided by Kathleen M Dorries, PhD, of Peloton Advantage and by Michelle Jenvey, PhD, of Engage Scientific and was funded by Pfizer Inc. 

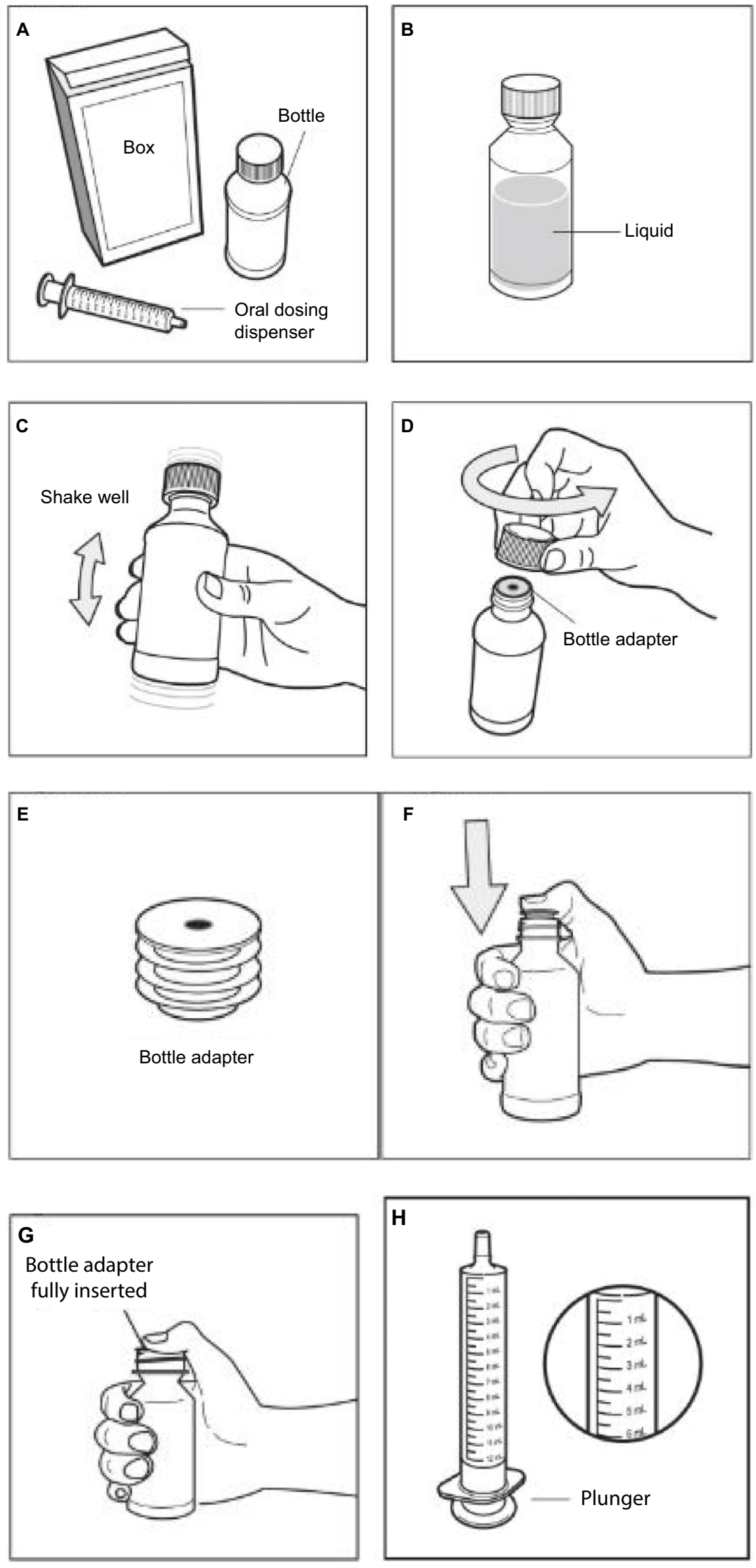

Figure I (Continued) 

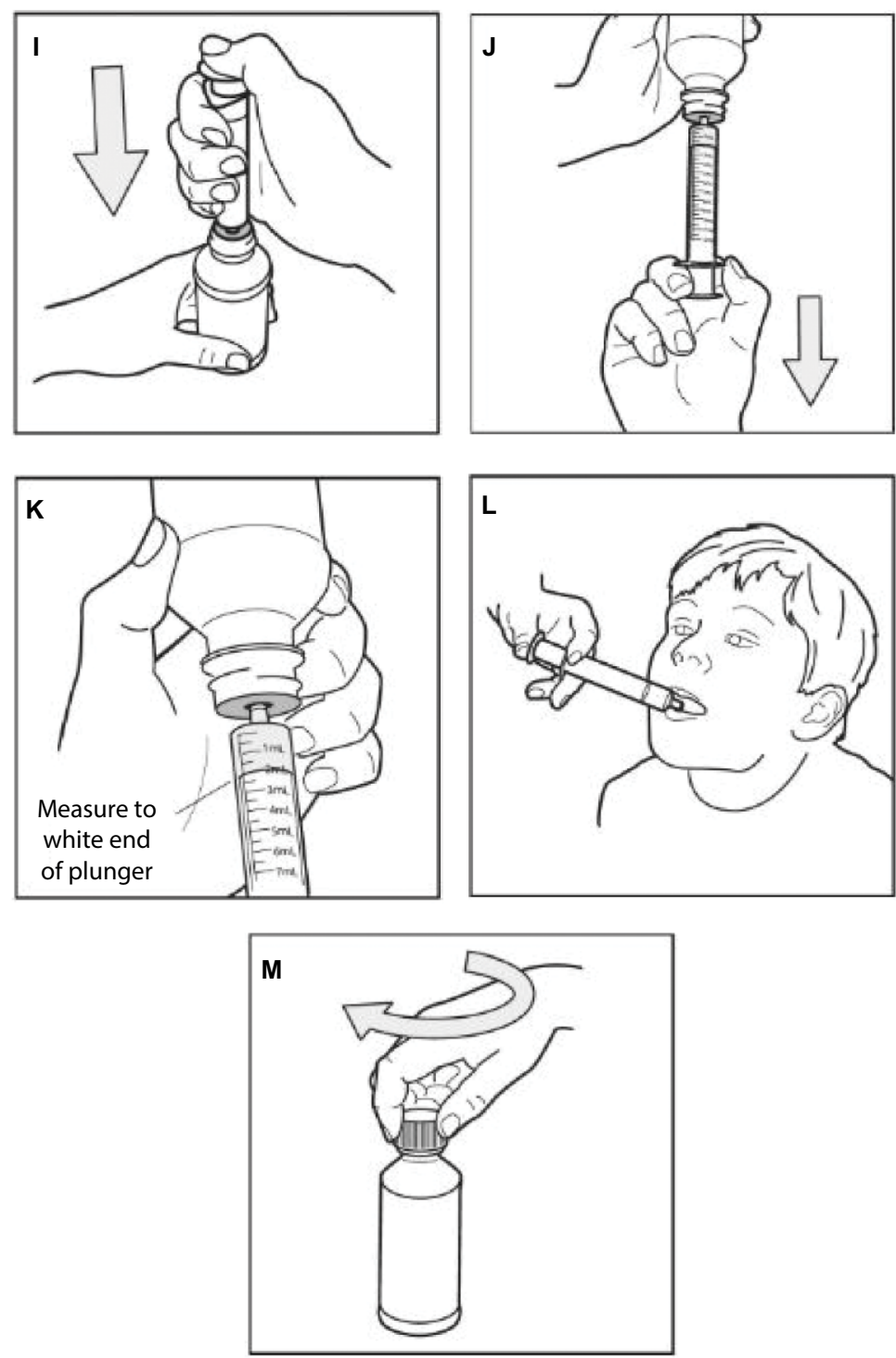

Figure I MEROS (Quillivant XR) instructions for use. ${ }^{42}$

Notes: Step I. Remove the MEROS bottle and oral dosing dispenser from the box (A). If the oral dosing dispenser is missing or not provided, please contact your pharmacist for a replacement. Step 2. Check and make sure that the MEROS bottle contains liquid medicine (B). If MEROS is still in powder form, do not use it. Return it to your pharmacist. Step 3. Shake the bottle well (up and down) for at least 10 seconds before each use (C). Step 4 . Uncap the bottle and check that the bottle adapter has been fully inserted into the bottle (D). If bottle adapter (E) has not been inserted by the pharmacist into the bottle, insert adapter into the bottle as shown (F and $\mathbf{G})$. Once the bottle adapter has been fully inserted into the bottle $(\mathbf{G})$, it should not be removed. If the bottle adapter has not been inserted and is missing from the box, contact your pharmacist. The bottle adapter must be fully inserted and should be flush against the mouth of the bottle and must remain in place to allow the child-resistant cap to engage. Step 5. Check the MEROS dose in milliliters as prescribed by your doctor. Locate this number on the oral dosing dispenser $(\mathbf{H})$. Step 6. Insert tip of the oral dosing dispenser into the upright bottle and push the plunger all the way down (I). Step 7. With the oral dosing dispenser in place, turn the bottle upside down. Pull the plunger to the number of milliliters you need (the amount of liquid medicine in Step $5[\mathrm{~J}])$. Measure the number of milliliters of medicine from the white end of the plunger (K). Step 8. Remove the oral dosing dispenser from the bottle adapter. Step 9. Slowly squirt MEROS directly into your or your child's mouth (L). Step 10. Cap the bottle tightly. Store the bottle upright at $59^{\circ} \mathrm{F}-86^{\circ} \mathrm{F}\left(15^{\circ} \mathrm{C}-30^{\circ} \mathrm{C} ; \mathbf{M}\right)$.

Abbreviation: MEROS, methylphenidate extended-release oral suspension; XR, extended release.

\section{Disclosure}

$\mathrm{JC}$ declares that he has no conflict of interest. EHD and FW are employees of Pfizer Inc. HWB was a paid consultant to Pfizer in connection with the development of the manuscript. The authors report no other conflicts of interest in this work.

\section{References}

1. Vaidya CJ. Neurodevelopmental abnormalities in ADHD. Curr Top Behav Neurosci. 2012;9:49-66.

2. Pliszka S, AACAP Work Group on Quality Issues. Practice parameter for the assessment and treatment of children and adolescents with attention-deficit/hyperactivity disorder. J Am Acad Child Adolesc Psychiatry. 2007;46(7):894-921. 
3. Budur K, Mathews M, Adetunji B, Mathews M, Mahmud J. Nonstimulant treatment for attention deficit hyperactivity disorder. Psychiatry (Edgmont). 2005;2(7):44-48.

4. Barbaresi WJ, Colligan RC, Weaver AL, Voigt RG, Killian JM, Katusic SK. Mortality, ADHD, and psychosocial adversity in adults with childhood ADHD: a prospective study. Pediatrics. 2013;131(4):637-644.

5. Barkley RA, Fischer M, Edelbrock CS, Smallish L. The adolescent outcome of hyperactive children diagnosed by research criteria: I. An 8-year prospective follow-up study. JAm Acad Child Adolesc Psychiatry. 1990;29(4):546-557.

6. Harpin VA. The effect of ADHD on the life of an individual, their family, and community from preschool to adult life. Arch Dis Child. 2005;90(suppl 1):i2-i7.

7. Hoza B, Mrug S, Gerdes AC, et al. What aspects of peer relationships are impaired in children with attention-deficit/hyperactivity disorder? J Consult Clin Psychol. 2005;73(3):411-423.

8. Kessler RC, Adler L, Barkley R, et al. The prevalence and correlates of adult ADHD in the United States: results from the National Comorbidity Survey Replication. Am J Psychiatry. 2006;163(4):716-723.

9. Faraone SV, Wilens TE, Petty C, Antshel K, Spencer T, Biederman J. Substance use among ADHD adults: implications of late onset and subthreshold diagnoses. Am J Addict. 2007;16(suppl 1):24-32.

10. Leibson CL, Barbaresi WJ, Ransom J, et al. Emergency department use and costs for youth with attention-deficit/hyperactivity disorder: associations with stimulant treatment. Ambul Pediatr. 2006;6(1):45-53.

11. Doshi JA, Hodgkins P, Kahle J, et al. Economic impact of childhood and adult attention-deficit/hyperactivity disorder in the United States. J Am Acad Child Adolesc Psychiatry. 2012;51(10):990-1002.

12. Froehlich TE, Lanphear BP, Epstein JN, Barbaresi WJ, Katusic SK, Kahn RS. Prevalence, recognition, and treatment of attention-deficit/ hyperactivity disorder in a national sample of US children. Arch Pediatr Adolesc Med. 2007;161(9):857-864.

13. Ginsberg Y, Quintero J, Anand E, Casillas M, Upadhyaya HP. Underdiagnosis of attention-deficit/hyperactivity disorder in adult patients: a review of the literature. Prim Care Companion CNS Disord. 2014;16(3):13r01600.

14. Subcommittee on Attention-Deficit/Hyperactivity Disorder, Steering Committee on Quality Improvement and Management, Wolraich M, et al. ADHD: clinical practice guideline for the diagnosis, evaluation, and treatment of attention-deficit/hyperactivity disorder in children and adolescents. Pediatrics. 2011;128(5):1007-1022.

15. Childress AC. A critical appraisal of atomoxetine in the management of ADHD. Ther Clin Risk Manag. 2016;12:27-39.

16. Greenhill LL, Pliszka S, Dulcan MK, et al. Practice parameter for the use of stimulant medications in the treatment of children, adolescents, and adults. JAm Acad Child Adolesc Psychiatry. 2002;41(2 suppl):26S-49S.

17. Park P, Caballero J, Omidian H. Use of serotonin norepinephrine reuptake inhibitors in the treatment of attention-deficit hyperactivity disorder in pediatrics. Ann Pharmacother. 2014;48(1):86-92.

18. Strattera [package insert]. Indianapolis, IN: Eli Lilly and Company; 2015.

19. Intuniv [package insert]. Lexington, MA: Shire US Inc.; 2016.

20. Kapvay [package insert]. St. Michael, Barbados: Concordia Pharmaceuticals; 2016.

21. McClain EK, Burks EJ. Managing attention-deficit/hyperactivity disorder in children and adolescents. Prim Care. 2015;42(1):99-112.

22. Hodgkins P, Shaw M, Coghill D, Hechtman L. Amfetamine and methylphenidate medications for attention-deficit/hyperactivity disorder: complementary treatment options. Eur Child Adolesc Psychiatry. 2012;21(9):477-492.

23. Ramos-Quiroga JA, Montoya A, Kutzelnigg A, Deberdt W, Sobanski E. Attention deficit hyperactivity disorder in the European adult population: prevalence, disease awareness, and treatment guidelines. Curr Med Res Opin. 2013;29(9):1093-1104.

24. Canadian Agency for Drugs and Technologies in Health (CADTH). Guidelines and Recommendations for ADHD in Children and Adolescents. Ottawa, ON: Canadian Agency for Drugs and Technologies in Health (CADTH); 2011.
25. Scheffler RM, Hinshaw SP, Modrek S, Levine P. The global market for ADHD medications. Health Aff (Millwood). 2007;26(2):450-457.

26. Cascade E, Kalali AH, Weisler RH. Short-acting versus long-acting Medications for the treatment of ADHD. Psychiatry (Edgmont). 2008;5(8):24-27.

27. Findling RL, Dinh S. Transdermal therapy for attention-deficit hyperactivity disorder with the methylphenidate patch (MTS). CNS Drugs. 2014;28(3):217-228.

28. Meltzer EO, Welch MJ, Ostrom NK. Pill swallowing ability and training in children 6 to 11 years of age. Clin Pediatr (Phila). 2006;45(8): 725-733.

29. Polaha J, Dalton WT 3rd, Lancaster BM. Parental report of medication acceptance among youth: implications for everyday practice. South Med J. 2008;101(11):1106-1112.

30. Hansen DL, Tulinius D, Hansen EH. Adolescents' struggles with swallowing tablets: barriers, strategies and learning. Pharm World Sci. 2008;30(1):65-69.

31. Focalin [package insert]. East Hanover, NJ: Novartis Pharmaceuticals Corporation; 2017.

32. Metadate CD [package insert]. Smyrna, GA: UCB, Inc.; 2017.

33. Vyvanse [package insert]. Lexington, MA: Shire US Inc.; 2017.

34. Childress A, Sallee FR. The use of methylphenidate hydrochloride extended-release oral suspension for the treatment of ADHD. Expert Rev Neurother. 2013;13(9):979-988.

35. Childress AC, Berry SA. The single-dose pharmacokinetics of NWP06, a novel extended-release methylphenidate oral suspension. Postgrad Med. 2010;122(5):35-41.

36. Faraone SV, Biederman J, Spencer TJ, Aleardi M. Comparing the efficacy of medications for ADHD using meta-analysis. MedGenMed. 2006;8(4):4.

37. Faraone SV, Glatt SJ. A comparison of the efficacy of medications for adult attention-deficit/hyperactivity disorder using meta-analysis of effect sizes. J Clin Psychiatry. 2010;71(6):754-763.

38. Manos MJ, Tom-Revzon C, Bukstein OG, Crismon ML. Changes and challenges: managing ADHD in a fast-paced world. $J$ Manag Care Pharm. 2007;13(9 suppl B):S2-S13.

39. Vetter VL, Elia J, Erickson C, et al. Cardiovascular monitoring of children and adolescents with heart disease receiving medications for attention deficit/hyperactivity disorder [corrected]: a scientific statement from the American Heart Association Council on Cardiovascular Disease in the Young Congenital Cardiac Defects Committee and the Council on Cardiovascular Nursing. Circulation. 2008;117(18):2407-2423.

40. Brown CH [webpage on the Internet]. Attention-Deficit/Hyperactivity Disorder and Treatment. 2011. Available from: http://www.pharmacytimes.com/ publications/issue/2011/march2011/adhd-0311. Accessed March 14, 2016.

41. U.S. Department of Justice, Drug Enforcement Administration [webpage on the Internet]. Controlled Substances Security Manual. 2016. Available from: http://www.deadiversion.usdoj.gov/pubs/manuals/sec/ app_law.htm. Accessed March 14, 2016.

42. Quillivant XR [package insert]. New York, NY: NextWave Pharmaceuticals, Inc; A subsidiary of Pfizer Inc.; 2017.

43. Drugs.com [webpage on the Internet]. FDA Approves Quillivant XR. NextWave Pharmaceuticals Receives FDA Approval of Quillivant XR for Once-Daily Treatment of ADHD. 2012. Available from: http://www. drugs.com/newdrugs/nextwave-pharmaceuticals-receives-fda-approvalquillivant-xr-once-daily-adhd-3519.html. Accessed September 1, 2017.

44. Wigal SB, Childress AC, Belden HW, Berry SA. NWP06, an extendedrelease oral suspension of methylphenidate, improved attention-deficit/ hyperactivity disorder symptoms compared with placebo in a laboratory classroom study. J Child Adolesc Psychopharmacol. 2013;23(1):3-10.

45. Wigal SB, Gupta S, Guinta D, Swanson JM. Reliability and validity of the SKAMP rating scale in a laboratory school setting. Psychopharmacol Bull. 1998;34(1):47-53.

46. Wigal SB, Wigal TL. The laboratory school protocol: its origin, use, and new applications. J Atten Disord. 2006;10(1):92-111.

47. DuPaul GJ, Power TJ, Anastopoulos AD, Reid R. ADHD Rating Scale - IV: Checklists, Norms, and Clinical Interpretation. New York, NY: The Guilford Press; 1998. 
48. Guy W, editor. CGI clinical global impressions. ECDEU Assessment Manual for Psychopharmacology Revised, 1976. Rockville, MD, USA: US Department Health Education and Welfare, National Institute of Mental Health; 1976:217-222.

49. Robb AS, Findling RL, Childress AC, Berry SA, Belden HW, Wigal SB. Efficacy, safety, and tolerability of a novel methylphenidate extendedrelease oral suspension (MEROS) in ADHD. JAtten Disord. Epub 2014 May 29.

50. Hamed AM, Kauer AJ, Stevens HE. Why the diagnosis of attention deficit hyperactivity disorder matters. Front Psychiatry. 2015;6:168.

51. Mueller AK, Fuermaier AB, Koerts J, Tucha L. Stigma in attention deficit hyperactivity disorder. Atten Defic Hyperact Disord. 2012;4(3):101-114.

52. Glass BD, Haywood A. Stability considerations in liquid dosage forms extemporaneously prepared from commercially available products. J Pharm Pharm Sci. 2006;9(3):398-426.

53. Caballero J. Attention-deficit/hyperactivity disorder. In: Benavides S, Nahata MC, editors. Pediatric Pharmacotherapy. Lenexa, KS: American College of Clinical Pharmacy; 2013:435-448

54. Adderall [package insert]. Horsham, PA: Teva Select Brands; 2017.

55. Adderall XR [package insert]. Lexington, MA: Shire US Inc.; 2017.

56. Adzenys XR-ODT [package insert]. Grand Prairie, TX: Neos Therapeutics, Inc.; 2017.

57. Dexedrine [package insert]. Horsham, PA: Amedra Pharmaceuticals, LLC; 2017.
58. Dyanavel XR [package insert]. Monmouth Junction, NJ: Tris Pharma, Inc.; 2017.

59. Evekeo [package insert]. Atlanta, GA: Arbor Pharmaceuticals; 2016.

60. ProCentra [package insert]. Newport, KY: Independence Pharmaceuticals; 2015.

61. Aptensio XR [package insert]. Coventry, RI: Rhodes Pharmaceuticals; 2017.

62. Concerta [package insert]. Titusville, NJ: Janssen Pharmaceuticals, Inc.; 2017.

63. Daytrana [package insert]. Miami, FL: Noven Therapeutics, LLC; 2017.

64. Focalin XR [package insert]. East Hanover, NJ: Novartis Pharmaceuticals Corporation; 2017.

65. Metadate ER [package insert]. Smyra, GA: Upstate Pharma; 2016.

66. Methylin Oral Solution [package insert]. Florham Park, NJ: Shionogi Inc.; 2017.

67. Methylin ER [package insert]. Hazelwood, MO: Mallinckrodt; 2016.

68. Quillichew ER [package insert]. New York, NY: NextWave Pharmaceuticals, Inc.; 2016.

69. Ritalin-SR [package insert]. East Hanover, NJ: Novartis Pharmaceuticals Corporation; 2017.

70. Ritalin LA [package insert]. East Hanover, NJ: Novartis Pharmaceuticals Corporation; 2017.
Integrated Pharmacy Research and Practice

\section{Publish your work in this journal}

Integrated Pharmacy Research and Practice is an international, peer-reviewed, open access, online journal, publishing original research, reports, reviews and commentaries on all areas of academic and professional pharmacy practice. This journal aims to represent the academic output of pharmacists and pharmacy practice with particular focus on integrated care. All papers are carefully

\section{Dovepress}

peer reviewed to ensure the highest standards as well as ensuring that we are informing and stimulating pharmaceutical professionals. The manuscript management system is completely online and includes a very quick and fair peer-review system, which is all easy to use. Visit http://www.dovepress.com/ testimonials.php to read real quotes from published authors.

Submit your manuscript here: http://www.dovepress.com/integrated-pharmacy-research-and-practice-journal 